\title{
Overweight and obesity in type 1 diabetes equal those of the general population
}

\author{
Paul Fellinger · David Fuchs · Peter Wolf · Georg Heinze · Anton Luger · Michael Krebs · Yvonne Winhofer
}

Received: 10 October 2018 / Accepted: 11 December 2018 / Published online: 7 January 2019

(C) The Author(s) 2019

\begin{abstract}
Summary
Background The obesity epidemic might affect patients with type 1 diabetes (T1DM), historically described as lean and insulin-sensitive subjects. Insulin resistance in T1DM might increase diabetic complications, especially cardiovascular disease. Therefore, the body mass index (BMI) in T1DM patients was analyzed in comparison to the general population. Furthermore, the impact of increased BMI on glycemic control and metabolic alterations was assessed.

Methods Body mass index was compared overall and among four different age groups between adult T1DM $(n=186)$, treated in the outpatient clinic between 2014 and 2016, and 15,771 individuals from the general population who took part at an Austrian health survey. Furthermore, parameters of glycemic control, lipid state, blood pressure and additional medication were compared between T1DM with a BMI under or above $27.5 \mathrm{~kg} / \mathrm{m}^{2}$.

Results Patients with T1DM had significantly higher BMI values than general population $\left(25.9 \pm 4.2 \mathrm{~kg} / \mathrm{m}^{2}\right.$ vs. $25.3 \pm 4.5 \mathrm{~kg} / \mathrm{m}^{2} ; \quad p=0.027$ ), controlling for age group; however, prevalence of overweight $(39.8 \%$ vs. $33.1 \%$ ) and obesity (14\% vs. $13.8 \%$ ) was not significantly different. Within the 4 age groups only T1DM patients between 30 years and 49 years old had significantly higher BMI values compared to the general
\end{abstract}

P. Fellinger $\cdot$ D. Fuchs $\cdot$ P. Wolf $\cdot$ A. Luger $\cdot$ M. Krebs ·

Y. Winhofer $(\triangle)$

Division of Endocrinology and Metabolism, Department of

Internal Medicine III, Medical University of Vienna,

Währinger Gürtel 18-20, 1090 Vienna, Austria

yvonne.winhofer@meduniwien.ac.at

G. Heinze

Section for Clinical Biometrics, Center for Medical Statistics, Informatics, and Intelligent Systems, Medical University of

Vienna, Spitalgasse 23, 1090 Vienna, Austria population (mean difference $1.9 \mathrm{~kg} / \mathrm{m}^{2} ; 95 \%$ confidence interval, CI: $0.96-2.83 \mathrm{~kg} / \mathrm{m}^{2}$ ). In T1DM, a BMI $\geq 27.5 \mathrm{~kg} / \mathrm{m}^{2}$ was associated with increased rates of hypertension, dyslipidemia, microalbuminuria, and increased insulin demand, whereas glycemic control was not affected.

Conclusions In contrast to common descriptions T1DM patients have a higher BMI compared to the general population. Rates of overweight and obesity in T1DM equal those of the general population. Therefore, it is concluded that the obesity epidemic has reached T1DM patients and "double diabetes" might be an entity to consider.

Keywords Cardiovascular risk factors - Double diabetes - Insulin resistance - Cardiometabolic risk - Epidemiology

\section{Introduction}

Patients with type 1 diabetes mellitus (T1DM) have traditionally been described as lean and insulin-sensitive subjects, in whom absolute insulin deficiency rather than insulin resistance is the main pathophysiological mechanism behind chronic hyperglycemia. In recent years a substantial increase in overweight and obesity in the general population across the globe was observed, talking about an obesity epidemic with around $18 \%$ of the western European population being obese [1-3]. Overweight and obesity are associated with the development of insulin resistance and consequent hyperinsulinemia, dyslipidemia and subclinical inflammation, which are all metabolic disturbances that result in the development of cardiovascular and malignant diseases [3-5]. This trend might also affect T1DM patients as suspected by previous reports [6-9].

In T1DM, especially microangiopathic complications, such as nephropathy and retinopathy, have 
been considered as the leading complications, causing a poor prognosis and quality of life in affected patients [10]. Fortunately, the incidence and severity of these complications have decreased in the last decades due to improved glycemic control by intensive insulin therapy [11, 12]; however, tight glycemic control is also associated with weight gain and an increased risk of hypoglycemia [12]. Weight gain in patients with T1DM might trigger the same metabolic disturbances as seen in patients with type 2 diabetes, and thus some authors suggest using the term "double diabetes", describing the occurrence of insulin resistance in T1DM [6, 13]. Consequently, the risk for developing cardiovascular disease, the main cause of death in the population, might be even higher in these patients. As previously shown the risk of death is still doubled even in T1DM patients with good glycemic control (HbAlC <7\%; <42 mmol/mol), mainly driven by cardiovascular death, and particularly women with T1DM are at special risk [14]. Hence, long-term survival in T1DM has still not reached the expected goals. Reasons for the increased mortality should be elucidated to find appropriate treatment strategies.

There is a lack of knowledge whether the rates of overweight and obesity are comparable to the general population, therefore the aim of this study was to assess the prevalence of overweight and obesity in a sample of Austrian type 1 diabetes patients in comparison with a large representative sample of the Austrian population. Furthermore, the aim was to assess whether overweight/obese patients with T1DM have worse glycemic control and metabolic alterations implicating an increased cardiovascular risk.

\section{Materials and methods}

In this retrospective, cross sectional study all adult patients with T1DM $(n=186)$ consecutively seen between July 2014 and January 2016 in the diabetes outpatient clinic at the General Hospital in Vienna, Austria were included. If patients had multiple consultations during the observational period, the first visit during that period was used in the analyses. Type I diabetes mellitus was diagnosed based on permanent insulin treatment and positive markers for autoimmune destruction of the islet cells. The dataset of the Austrian health survey 2014 included 15,771 individuals with information about age class (5-year intervals), height, weight, and history of diabetes was provided by Statistics Austria [15]. The protocol was approved by the ethics committee of the Medical University of Vienna, protocol number 1635/2016.

\section{Measurements}

Physical, clinical as well as laboratory data was retrieved from the medical files of the patients. Weight and height were measured using standardized methods and BMI calculated as weight $(\mathrm{kg})$ divided by height squared $\left(\mathrm{m}^{2}\right)$. Overweight and obesity were defined according to current WHO criteria as BMI $25-30 \mathrm{~kg} / \mathrm{m}^{2}$ and $\geq 30 \mathrm{~kg} / \mathrm{m}^{2}$, respectively. Due to $\mathrm{lim}$ ited number of patients in the category obesity for further analysis patients were divided into a group with a BMI less than $27.5 \mathrm{~kg} / \mathrm{m}^{2}$ and a group with BMI above $27.5 \mathrm{~kg} / \mathrm{m}^{2}$, in accordance with previously published protocols [16, 17].

Patient age was recorded at the day of visit and noted in full years, whereas in the health survey sample age was available only in 5-year steps beginning with the group of 15-19 years up to more than 85 years. For further analysis, patients as well as the population were divided into 4 age groups, namely <30, 30-49, 50-69 and >69 years. The level of haemoglobin Alc (HbAlc) was used as a marker for glycemic control and further categorized in good $(<7.5 \%$; $<58 \mathrm{mmol} / \mathrm{mol})$, intermediate $(7.5-9 \% ; 58-75 \mathrm{mmol} / \mathrm{mol})$ and poor $(>9 \%$; $>75 \mathrm{mmol} / \mathrm{mol}$ ) glycemic control. For evaluation of kidney disease, the albumin to creatinine ratio was measured and according to the American Diabetes Association (ADA) classification of microalbuminuria values below $30 \mu \mathrm{g} / \mathrm{mg}$ defined as normal, values between $30-300 \mu \mathrm{g} / \mathrm{mg}$ as microalbuminuria, and values $>300 \mu \mathrm{g} / \mathrm{mg}$ as macroalbuminuria [18]. Triglycerides, low-density lipoprotein (LDL), high-density lipoprotein (HDL), and total cholesterol levels were recorded and used for analysis of the lipid metabolism. Data about daily basal as well as bolus insulin dosage were also retrieved from the medical files and for further analysis divided by body weight (in $\mathrm{kg}$ ) as well as by body surface area which was calculated using the Mosteller formula [19].

\section{Statistical analysis}

Data were analyzed descriptively and presented either with mean and standard deviation or median and interquartile ranges, depending on the distribution of the data. The two-sided significance level was defined as $\alpha=0.05$.

Student's $t$-test was used for comparison of means, while the $\chi^{2}$-test was used to compare frequencies of categorical variables. The two-way analysis of variance (ANOVA) was used to compare the mean BMI between patients and the reference population while controlling for age group, and to evaluate the interaction of age and T1DM status. All analyses were performed using SPSS version 21 (SPSS, Chicago, IL, USA).

\section{Results}

\section{Comparison between T1DM and the general population}

Data from 186 T1DM patients were available for analyses. Of these 186 T1DM patients, $48.9 \%$ were female 
Table 1 Baseline characteristics T1DM and general population

\begin{tabular}{|c|c|c|c|}
\hline Parameter & T1DM-mean (SD) & General population (SD) & $P$-Value \\
\hline Age (years) & $45(15)$ & $45-49(10)$ & ns \\
\hline$<30$ years: $N(\%)$ & $32(17.2)$ & $2456(15.6)$ & \multirow[t]{4}{*}{ ns } \\
\hline 30-49years: $N(\%)$ & $79(42.5)$ & $6034(38.3)$ & \\
\hline 50-69years: $N(\%)$ & 65 (34.9) & $5697(36.1)$ & \\
\hline$>70 \mathrm{y}: N(\%)$ & $10(5.4)$ & $1584(10)$ & \\
\hline Sex m:f (\%) & $51: 49$ & $44: 56$ & ns \\
\hline$B M I\left(\mathrm{~kg} / \mathrm{m}^{2}\right)$ & $25.9(4.19)$ & $25.3(4.5)$ & 0.027 \\
\hline$<25 \mathrm{~kg} / \mathrm{m}^{2}: N(\%)$ & $86(46)$ & $8383(53.2)$ & \multirow[t]{3}{*}{ ns } \\
\hline $25-<30 \mathrm{~kg} / \mathrm{m}^{2}: N(\%)$ & $74(39.8)$ & $5218(33.1)$ & \\
\hline$\geq 30 \mathrm{~kg} / \mathrm{m}^{2}: N(\%)$ & $26(14)$ & $2170(13.8)$ & \\
\hline \multicolumn{4}{|l|}{ BMI by age groups } \\
\hline$<30$ years $\left(\mathrm{kg} / \mathrm{m}^{2}\right)$ & $23.7(4.0)$ & $23.3(4.0)$ & ns \\
\hline 30-49years $\left(\mathrm{kg} / \mathrm{m}^{2}\right)$ & $26.7(4.4)$ & $24.8(4.3)$ & $<0.001$ \\
\hline 50-69 years $\left(\mathrm{kg} / \mathrm{m}^{2}\right)$ & $26.1(3.8)$ & $26.4(4.5)$ & ns \\
\hline$>70$ years $\left(\mathrm{kg} / \mathrm{m}^{2}\right)$ & $25.6(3.0)$ & $26.4(4.1)$ & ns \\
\hline
\end{tabular}

Table 2 Patient characteristics-normal weight vs. overweight T1DM patients

\begin{tabular}{|c|c|c|c|}
\hline \multirow[t]{2}{*}{ Variables } & \multicolumn{2}{|l|}{ BMI } & \multirow[t]{2}{*}{$P$-value } \\
\hline & $<27.5 \mathrm{~kg} / \mathrm{m}^{2}$ & $\geq 27.5 \mathrm{~kg} / \mathrm{m}^{2}$ & \\
\hline Women: $N(\%)$ & $65(50.8)$ & $26(44.8)$ & ns \\
\hline Diabetes duration (years) & $18.6 \pm 12.7$ & $20.8 \pm 12.5$ & ns \\
\hline Age (years) & $44 \pm 16$ & $47 \pm 13$ & ns \\
\hline $\mathrm{HbA} 1 \mathrm{c}(\% / \mathrm{mmol} / \mathrm{mol})$ & $7.7 \pm 1.4 / 61 \pm 15$ & $7.8 \pm 1.1 / 62 \pm 12$ & ns \\
\hline $\mathrm{HbA} 1 \mathrm{c}>7.5 \%(58 \mathrm{mmol} / \mathrm{mol}): N(\%)$ & $63(49.2)$ & $35(60.3)$ & ns \\
\hline Arterial hypertension: $N(\%)$ & $72(60)$ & $46(82.1)$ & 0.004 \\
\hline Systolic BP (mm Hg) & $133.2 \pm 17.9$ & $143.2(21.7)$ & 0.001 \\
\hline Diastolic BP (mm Hg) & $80.0 \pm 9.1$ & $85.2 \pm 12.8$ & 0.002 \\
\hline Basal insulin dose (IU) & $20.1 \pm 10$ & $30.3 \pm 11.4$ & $<0.001$ \\
\hline Insulin (IU/m²/d) & $10.9 \pm 5.1$ & $14.4 \pm 5.1$ & $<0.001$ \\
\hline Insulin (IU/kg/d) & $0.28 \pm 0.13$ & $0.33 \pm 0.12$ & 0.017 \\
\hline Creatinine (mg/dl) & $0.9 \pm 0.9$ & $0.9 \pm 0.2$ & ns \\
\hline Dyslipidemia: $N(\%)$ & $18(16.1)$ & $19(40.4)$ & 0.002 \\
\hline Triglyceride (mg/dl) & $90.8 \pm 45.3$ & $120.6 \pm 53.2$ & $<0.001$ \\
\hline Cholesterol (mg/dl) & $182.6 \pm 37$ & $173.8 \pm 37.1$ & ns \\
\hline $\mathrm{HDL}(\mathrm{mg} / \mathrm{dl})$ & $69.5 \pm 20.6$ & $56.1 \pm 13.8$ & $<0.001$ \\
\hline LDL (mg/dl) & $92.3 \pm 33.1$ & $82.9 \pm 22.6$ & ns \\
\hline Non-HDL-cholesterol (mg/dl) & $113.2 \pm 36.9$ & $118.3 \pm 37.8$ & ns \\
\hline Albuminuria: $N(\%)$ & $7(7.8)$ & $12(30)$ & 0.001 \\
\hline Microalbuminuria (\%) & $5(5.6)$ & $10(25)$ & 0.003 \\
\hline Macroalbuminuria (\%) & $2(2.2)$ & $2(5)$ & ns \\
\hline
\end{tabular}

and $51.1 \%$ male with a mean age of $45 \pm 15$ years. The sample of the general Austrian population comprised 15,771 individuals, with the median age group between 45 and 49 years and an interquartile range of \pm 10 years. Baseline characteristics are shown in Table 1 . Of the general population $4.7 \%$ reported having a diagnosis of diabetes, without further differentiation.

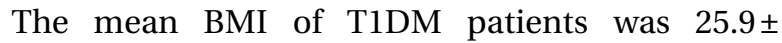
$4.2 \mathrm{~kg} / \mathrm{m}^{2}$ and, controlling for age group, significantly higher than the mean BMI of the general population $\left(25.3 \pm 4.5 \mathrm{~kg} / \mathrm{m}^{2}, P=0.027\right)$. Fig. 1 shows a scatterplot of BMI by age overlaid with age-specific median and 25th and 75th percentiles of BMI calculated in the general population. Of T1DM patients, 64 (34.4\%) had a BMI higher than the age-specific 75th percentile, while only $46.5(25 \%)$ would be expected $(P=0.010)$. 
Fig. 1 Body mass index (BMI) of each T1DM in comparison with median, 25th and 75th percentile of general population in relation to age

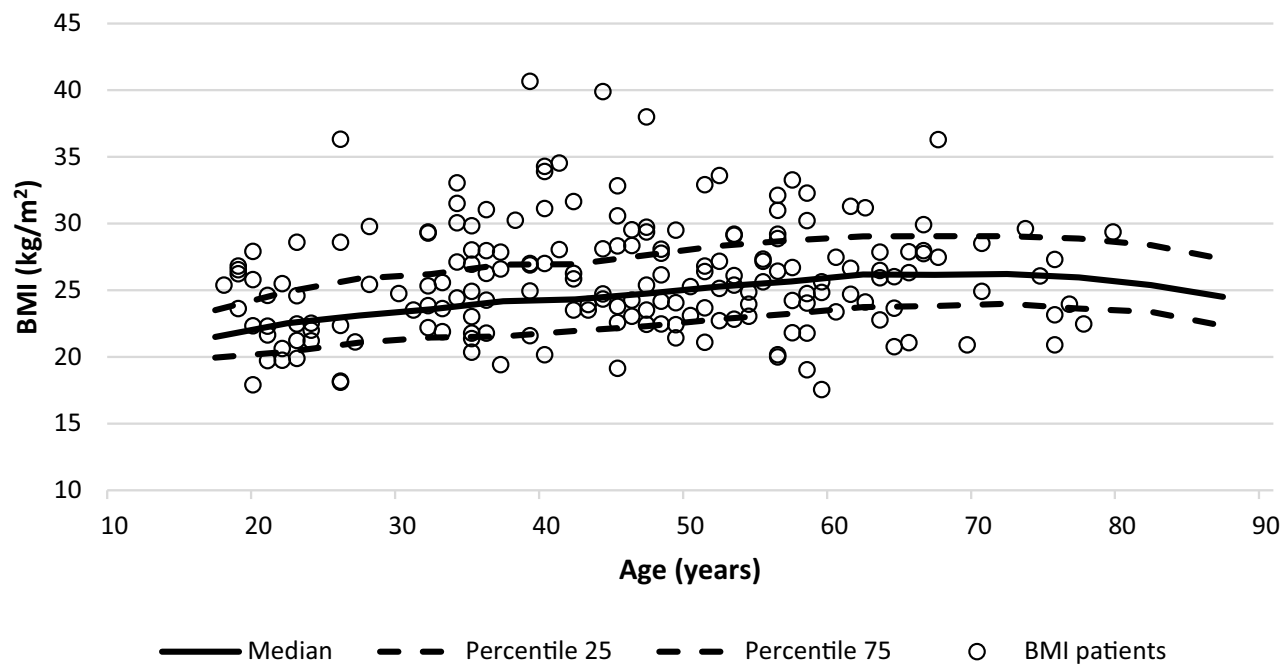

Applying the commonly used categories, $39.8 \%$ of T1DM patients and $33.1 \%$ of the general population were overweight. The prevalence of obesity was $14 \%$ in T1DM and $13.8 \%$ in the general population; however, the differences in prevalence of overweight and obesity were not significant.

Descriptive analyses of different age groups revealed that T1DM patients between 30 and 49 years had the highest BMI whereas in the general population BMI was highest in those aged 50-69 years (Table 1). In T1DM as well as in the general population the individuals younger than 30 years of age had the lowest mean BMI.

As ANOVA revealed evidence of heterogeneity in the differences in BMI between patients and the reference population across the age groups (interaction $P=0.017$ ), those differences were tested separately for the four age groups. A significantly higher BMI in T1DM patients than in the reference population only in the age group between 30 and 49 years $(26.7 \pm 4.4$ vs. $24.8 \pm 4.3 \mathrm{~kg} / \mathrm{m}^{2}$, corrected $p<0.001$ ). This was further evidenced by the number of T1DM patients with BMI higher than the age-specific 75th percentile (observed: 35 out of $79,44.3 \%$; expected: $19.75,25 \%$; $p<0.001)$. The BMI values were not significantly different in the other age groups. Within the age group of 30-49 years it appears that female T1DM patients were responsible for the higher BMI as they had higher BMI values than their healthy counterparts $(27.0 \pm 5.1$ vs. $\left.23.9 \pm 4.4 \mathrm{~kg} / \mathrm{m}^{2}, p<0.001\right)$ in contrary to male patients where no significant difference could be found.

\section{Metabolic parameters in T1DM}

In T1DM patients the median duration of diabetes was 17 years (interquartile range, IQR: 10-27) and mean HbAlc level was $7.7 \pm 1.3 \%(61 \pm 14 \mathrm{mmol} / \mathrm{mol})$ with $47.3 \%$ having good, $42.5 \%$ intermediate and $10.2 \%$ poor glycemic control. The average daily basal insulin dose was $23.4 \pm 11.5 \mathrm{IU}$ and 30 patients had additional antidiabetic medication, like metformin.

The T1DM patients had a mean systolic blood pressure of $136.4 \pm 19.7 \mathrm{~mm} \mathrm{Hg}$ and a mean diastolic pressure of $81.6 \pm 10.6 \mathrm{~mm} \mathrm{Hg}$, while $44 \%(n=78)$ had a diagnosis of arterial hypertension. Also, $14.6 \% \quad(n=19)$ had an albumin-creatinine-ratio above $30 \mathrm{mg} / \mathrm{dl}$ and were therefore diagnosed with albuminuria, with $11.5 \%(n=15)$ in the category for microalbuminuria and $3.1 \%(n=4)$ meeting the criteria for macroalbuminuria. Dyslipidemia was found in $23.3 \%$ of T1DM and in 27 prescriptions of statins was recorded. Further analysis showed that T1DM had cholesterol levels of $179.9 \pm 37.1 \mathrm{mg} / \mathrm{dl}$, LDL levels of $89 \pm 30 \mathrm{mg} / \mathrm{dl}$, HDL levels of $66 \pm 20 \mathrm{mg} / \mathrm{dl}$, and triglyceride levels of $100 \pm 50 \mathrm{mg} / \mathrm{dl}$.

There was no significant BMI difference between female and male T1DM $(25.6 \pm 4.4$ vs. $26.2 \pm 3.9$; $p=\mathrm{ns}$ ). As shown in Table 2, T1DM with a BMI $\geq 27.5 \mathrm{~kg} / \mathrm{m}^{2}$ had significantly higher systolic and diastolic blood pressure, higher triglyceride levels and lower HDL-cholesterol levels than T1DM with a BMI $<27.5 \mathrm{~kg} / \mathrm{m}^{2}$. In addition, they more often had complications like albuminuria, especially microalbuminuria. Furthermore, as expected, the basal insulin dose was significantly higher compared to T1DM with a BMI $<27.5 \mathrm{~kg} / \mathrm{m}^{2}$. After adjusting each patients' basal insulin dose by dividing it through their respective body weight the difference was still significant between the two groups. In contrast neither mean HbAlc nor prevalence of good or bad glycemic control was different between the BMI groups.

\section{Discussion}

This study showed that T1DM patients have higher BMI values compared to the general Austrian population. This finding is not in agreement with the common conception that T1DM patients are lean and insulin-sensitive individuals and should raise 
concern as higher BMI is associated with increased risk for cardiovascular complications [20, 21]. Other studies have also shown that the prevalence of overweight and obesity in T1DM has increased over the last years, mainly due to intensive insulin treatment and changes in diet $[7,22-24]$. With an average BMI of $25.9 \pm 4.2 \mathrm{~kg} / \mathrm{m}^{2}$ the T1DM population had a slightly higher BMI than a recent study of a large Austrian and German cohort $(n=31,119)$ which had an average BMI of $25.3 \pm 6.1 \mathrm{~kg} / \mathrm{m}^{2}$ [8]. Especially T1DM patients between 30 and 49 years had higher BMI values and seem to be the driving factor for higher BMI overall amongst T1DM compared to the general population, as no significantly different BMIs were found in the other age groups. The underlying reason for the significant difference in this age group is unclear. It was hypothesize that it could be associated with intensive insulin treatment, which the majority of this age group received since diagnosis. Furthermore, until recently weight management received little attention in the management of T1DM; however, the exact impact of overweight and obesity in T1DM on patient health is unclear. A recent study showed that the presence of the metabolic syndrome in T1DM was an independent risk factor for macrovascular and microvascular complications [8]. In contrast to that, other studies showed that an increase in BMI and even a $\mathrm{BMI}>30 \mathrm{~kg} / \mathrm{m}^{2}$ have beneficial effects on mortality in T1DM [25, 26]. In this study it was observed that patients with an increased BMI also have a higher prevalence of microvascular as well as macrovascular risk factors. Microalbuminuria was more frequent in overweight/obese T1DM, independently of glycemic control. This observation is in accordance with other studies which showed an impact of body weight on kidney disease in T1DM as well as another study where it was shown that young healthy obese people have a higher risk of albuminuria compared to lean people [7, 27, 28]. It is well accepted that microalbuminuria is not only a sign of beginning diabetic nephropathy but is also associated with the onset of cardiovascular disease in patients with diabetes [29]; however, data in patients with double diabetes are rare, and therefore studies are needed to further investigate the exact impact of overweight in T1DM and to better understand underlying pathophysiological processes in this growing group of patients.

Interestingly, this study showed that higher BMI values are not associated with worse glycemic control, which is in contrast to other studies where significant associations between metabolic syndrome and higher HbAlc levels were found [7, 27].

Thorn et al. showed that T1DM patients with metabolic syndrome had significantly worse cholesterol, triglyceride, as well as HDL levels [7]. In this study, however, overweight T1DM had only significant increased triglyceride and lower HDL levels, showing the typical dyslipidemia of patients with metabolic syndrome.

\section{Limitations}

This study has several limitations, including that the design was retrospective and carried out in a single center. Another limitation is that data regarding waist and hip circumference were missing and therefore it was not possible to calculate metabolic syndrome with the currently used criteria.

\section{Conclusion}

Te results of the study showed that the obesity-epidemic has also reached patients with T1DM, who have higher BMI values compared to the general population, especially between 30 and 49 years old. Insulin resistance in these patients might not only increase insulin demand, but also the risk for cardiometabolic complications. Further research is needed to assess the additional consequences of obesity in T1DM and to develop better methods and strategies for recognizing this problem at an early stage to prevent further negative consequences.

Funding Open access funding provided by Medical University of Vienna.

Conflict of interest P. Fellinger, D. Fuchs, P. Wolf, G. Heinze, A. Luger, M. Krebs, and Y. Winhofer declare that they have no competing interests.

Open Access This article is distributed under the terms of the Creative Commons Attribution 4.0 International License (http://creativecommons.org/licenses/by/4.0/), which permits unrestricted use, distribution, and reproduction in any medium, provided you give appropriate credit to the original author(s) and the source, provide a link to the Creative Commons license, and indicate if changes were made.

\section{References}

1. NCD Risk Factor Collaboration (NCD-RisC). Worldwide trends in body-mass index, underweight, overweight, and obesity from 1975 to 2016: a pooled analysis of 2416 population-based measurement studies in 128.9 million children, adolescents, and adults. Lancet. 2017; https:// doi.org/10.1016/S0140-6736(17)32129-3.

2. NCD Risk Factor Collaboration (NCD-RisC). Trends in adult body-mass index in 200 countries from 1975 to 2014: a pooled analysis of 1698 population-based measurement studies with 19.2 million participants. Lancet. 2016;387:1377-96.

3. The GBD 2015 Obesity Collaborators. Health effects of overweight and obesity in 195 countries over 25 years. NEnglJ Med. 2017;377:13-27.

4. Sanada H, Yokokawa H, Yoneda M, Yatabe J, Yatabe MS, Williams SM, et al. High body mass index is an important risk factor for the development of type 2 diabetes. Intern Med. 2012;51:1821-6.

5. Arai K, Yokoyama H, Okuguchi F, Yamazaki K, Takagi H, Hirao K, et al. Association between body mass index and core components of metabolic syndrome in 1486 patients with type 1 diabetes mellitus in Japan (JDDM 13). Endocr J. 2008;55:1025-32. 
6. Kilpatrick ES, Rigby AS, Atkin SL. Insulin resistance, the metabolic syndrome, and complication risk in type 1 diabetes: "double diabetes" in the Diabetes Control and Complications Trial. Diabetes Care. 2007;30:707-12.

7. Thorn LM, Forsblom C, Fagerudd J, Thomas MC, Pettersson-Fernholm K, Saraheimo M, et al. Metabolic syndrome in type 1 diabetes. Diabetes Care. 2005;28:2019-24.

8. Merger SR, Kerner W, Stadler M, Zeyfang A, Jehle P, MüllerKorbsch M, et al. Prevalence and comorbidities of double diabetes. Diabetes Res Clin Pract. 2016;119:48-56.

9. Polsky S, Ellis SL. Obesity, insulin resistance, and type 1 diabetes mellitus. Curr Opin Endocrinol Diabetes Obes. 2015;22:277-82.

10. Pambianco G, Costacou T, Ellis D, Becker DJ, Klein R, Orchard TJ. The 30-year natural history of type 1 diabetes complications: the Pittsburgh epidemiology of diabetes complications study experience. Diabetes. 2006;55:1463-9.

11. Diabetes Control and Complications Trial (DCCT), Epidemiology of Diabetes Interventions and Complications (EDIC) Study Research Group. Intensive diabetes treatment and cardiovascular outcomes in type 1 diabetes: the DCCT/EDIC study 30-year follow-up. Diabetes Care. 2016;39:686-93.

12. The Diabetes Control and Complications Trial (DCCT), Epidemiology of Diabetes Interventions and Complications (EDIC) Study Research Group. Intensive diabetes treatment and cardiovascular disease in patients with type 1 diabetes. NEngl J Med. 2005;353:2643-53.

13. Teupe B, Bergis K. Epidemiological evidence for "double diabetes". Lancet. 1991;337:361-2.

14. Lind M, Svensson A-M, Kosiborod M, Gudbjörnsdottir S, Pivodic A, Wedel H, et al. Glycemic control and excess mortality in type 1 diabetes. NEngl J Med. 2014;371:1972-82.

15. Klimont J, Baldaszti E. Österreichische Gesundheitsbefragung 2014. Hauptergebnisse des Austrian Health Interview Survey (ATHIS) und methodische Dokumentation. Wien: StatistikAustria; 2015.

16. Thompson D, Edelsberg J, Colditz GA, Bird AP, Oster G. Lifetime health and economic consequences of obesity. Arch Intern Med. 1999;159:2177-83.

17. Hammond RA, Levine R. The economic impact of obesity in the United States. Diabetes Metab Syndr Obes. 2010;3:285-95.

18. Haneda M, Utsunomiya K, Koya D, Babazono T, Moriya $\mathrm{T}$, Makino $\mathrm{H}$, et al. A new classification of diabetic nephropathy 2014: a report from joint committee on diabetic nephropathy. J Diabetes Investig. 2015;6:242-6.

19. Mosteller RD. Simplified calculation of body-surface area. NEngl J Med. 1987;317:1098.
20. Purnell JQ, Hokanson JE, Marcovina SM, Steffes MW, Cleary PA, Brunzell JD. Effect of excessive weight gain with intensive therapy of type 1 diabetes on lipid levels and blood pressure: results from the DCCT. Diabetes Control and Complications Trial. JAMA. 1998;280:140-6.

21. Purnell JQ, Zinman B, Brunzell JD. The effect of excess weight gain with intensive diabetes mellitus treatment on cardiovascular disease risk factors and atherosclerosis in type 1 diabetes mellitus clinical perspective: results from the Diabetes Control and Complications Trial/ Epidemiology of Diabetes Interventions and Complications (DCCT/EDIC) Study. Circulation. 2013;127:180-7.

22. Purnell JQ, Braffett BH, Zinman B, Gubitosi-Klug RA, Sivitz $\mathrm{W}$, Bantle JP, et al. Impact of excessive weight gain on cardiovascular outcomes in type 1 diabetes: results from the Diabetes Control and Complications Trial/Epidemiology of Diabetes Interventions and Complications (DCCT/EDIC) Study. Diabetes Care. 2017;40:1756-62.

23. Cleland SJ, Fisher BM, Colhoun HM, Sattar N, Petrie JR. Insulin resistance in type 1 diabetes: what is 'double diabetes' and what are the risks? Diabetologia. 2013;56:1462-70.

24. Stadler M, Bollow E, Fritsch M, Kerner W, SchuetzFuhrmann I, Krakow D, et al. Prevalence of elevated liver enzymes in adults with type 1 diabetes: a multicentre analysis of the German/Austrian DPV database. Diabetes Obes Metab. 2017;19:1171-8.

25. Conway B, Miller RG, Costacou T, Fried L, Kelsey S, Evans RW, et al. Adiposity and mortality in type 1 diabetes. Int J Obes (Lond). 2009;33:796-805.

26. Collier A, Connelly PJ, Hair M, Cameron L, Ghosh S, Waugh N. Mortality risk remains higher in individuals with type 1 diabetes: a population-based cohort study (the Ayrshire diabetes follow-up cohort [ADOC]). Diabetes Obes Metab. 2018; https://doi.org/10.1111/dom.13334.

27. Chillarón JJ, Flores Le-Roux JA, Benaiges D, Pedro-Botet J. Type 1 diabetes, metabolic syndrome and cardiovascular risk. Metabolism. 2014;63:181-7.

28. Ferris M, HoganSL, Chin H, ShohamDA, Gipson DS, Gibson $\mathrm{K}$, et al. Obesity, albuminuria, and urinalysis findings in US young adults from the Add Health Wave III Study. Clin J Am Soc Nephrol. 2007;2:1207-14.

29. Resl M, Vila G, Kraxner R, Pacher R, Luger A, Hülsmann $\mathrm{M}$, et al. Estimated glomerular filtration rate and albuminuria: true predictors of cardiovascular events in obese patients with type 2 diabetes? Wien Klin Wochenschr. 2013;125:629-33. 